\title{
Distributions and compositional patterns of polycyclic aromatic hydrocarbons (PAHs) and their derivatives in three edible fishes from Kharg coral Island, Persian Gulf, Iran
}

\begin{abstract}
This is the first report on bioaccumulation of polycyclic aromatic hydrocarbons (PAHs) and their derivatives (oxygen, nitrogen, sulfur, hydroxyl, carbonyl and methylcontaining PAHs) in three edible marine fishes, namely Lutjanus argentimaculatus, Lethrinus microdon and Scomberomorus guttatus, from Kharg Island, Persian Gulf, Iran. The concentrations (ng g-1dw) of $\Sigma 39 \mathrm{PAHs}$ resulted significantly higher in fish liver than muscle, with the PAH composition pattern dominated by low molecular weight compounds (naphthalene, alkyl-naphthalenes and phenanthrene). The highest mean concentrations of $\sum 9$ oxygenated and $\sum 15$ hydroxylated PAHs (ng g-1dw) were found ound in L. microdon and L. argentimaculatus, respectively, while the lowest values in S. guttatus. Additionally, the highest mean concentrations of $\Sigma 5$ carbonylic PAHs (ng g-1dw) were found in L. argentimaculatus, followed by L. microdon. The PAHs levels and distribution in fish liver and muscle were dependent on both the Kow of PAHs congeners and fish lipid contents. Overall, the present findings provide important baseline data for further research on the ecotoxicity of PAHs in aquatic organisms, and consequent implications for human health.
\end{abstract}

Keyword: PAHs; PAH derivatives; Edible fish; Muscle; Liver; Persian Gulf 
